\title{
Britas graduadas tratadas com cimento: uma avaliação de sua durabilidade sob o enfoque de porosidade, tenacidade e fratura
}

\author{
José Tadeu Balbo ${ }^{1}$
}

\begin{abstract}
Resumo: Uma análise de fadiga, fratura e de tenacidade permitiu a análise da capacidade de britas graduadas tratadas com cimento de resistirem a esforços repetitivos do tráfego. Verifica-se, por comparação com os concretos, que tal material apresenta elevada fragilidade, comportamento quase-frágil e baixíssima tenacidade, mesmo quando dosado em condições ótimas para melhoria de suas propriedades. Tais deficiências denotam com clareza, também por apoio em análise de porosidade em seções finas do material, analisadas microscopicamente, que a mistura cimentada sofre intenso processo de fratura, inclusive com intensa degradação modular durante testes de fadiga. Seu dimensionamento como camada de pavimento de qualquer espécie, nas condições verificadas, exigiria a minimização dos esforços de tração na flexão para contenção do processo de fratura, em limites não superiores a $50 \%$ da tensão de ruptura em tração do material.
\end{abstract}

\begin{abstract}
Fatigue, fracture and toughness tests carried out for cemented treated crushed stones allowed to infer on the material suitability to resist load repetition as pavement layer. It was found out low toughness, high brightness as well as quasi-brittle behavior, in comparison to conventional concretes, even when mix proportion is prepared to achieve the best mechanical properties. Such deficiencies, as denoted through its intense porosity evaluated from thin section microscopy, explains how the cemented treated material in induced to intense fracture process and modular degradation during repetitive loading. The analysis permits to consider that its design should be done, for any kind of pavement structure, for stress level under $50 \%$ of its tensile strength.
\end{abstract}

\section{INTRODUÇÃO}

Em artigo anterior, Balbo e Badawy (1993) exploraram o conceito de módulo de elasticidade de misturas de britas graduadas tratadas com cimento (BGTC), material bastante empregado no meio rodoviário nacional para a construção de bases de pavimentos rígidos (de concreto) e semi-rígidos. A importância da verificação estrutural das bases cimentadas em pavimentos asfálticos e de concreto foi posteriormente, do ponto de vista tensional, respectivamente discutida por Balbo (1996) e por Balbo e Rodolfo (2003).

Malgrado tais publicações enfatizem os aspectos de dimensionamento dessas bases cimentadas, em especial aquelas com misturas do tipo BGTC, uma releitura dos ensaios de fadiga conduzidos por Balbo (1993) seguida de análises de tenacidade e fratura do material, fazia-se necessária, em especial para que fossem evitados paralelismos entre aquele material e os concretos compactados com rolo, que surgem como alternativa para a construção dos pavimentos rígidoshíbridos (Balbo, 2005). Diante dessa perspectiva, julgava-se cabal a necessidade de perfeita diferenciação, do ponto de vista de fratura, entre ambos os materiais, bem como a discussão dos porquês das diferenças e das conseqüências práticas em termos de dimensionamento de camadas de pavimentos.

\footnotetext{
${ }^{1}$ José Tadeu Balbo, Escola Politécnica da Universidade de São Paulo. São Paulo, SP, Brasil (e-mail: jotbalbo@usp.br).
}

Este artigo é parte de TRANSPORTES, volume XIV, número 1, junho de 2006. ISSN: 1415-7713.
A presença de microfissuras tem efeito importante no valor do módulo de elasticidade dos materiais de natureza cerâmica, ou quase-frágeis, como é o caso de misturas do tipo solo-cimento ou BGTC, ou mesmo nos concretos, uma vez que elas diminuem a energia elástica armazenada, reduzindo o módulo de elasticidade efetivo do material. Salganik (1965) propôs modelo relacional entre o valor do módulo de elasticidade $(E)$, o módulo de elasticidade inicial $\left(E_{0}\right)$, o número de fissuras por unidade de volume $(N)$ e o raio médio de uma fissura $(a)$ :

$$
\frac{E}{E_{0}}=\left[1+\frac{16 \cdot\left(10-3 \cdot \mu_{0}\right) \cdot\left(1-\mu_{0}^{2}\right)}{45 \cdot\left(2-\mu_{0}\right)} \cdot N \cdot a^{3}\right]^{-1}
$$

sendo: $\mu_{0}$ o coeficiente de Poisson inicial do material. Na Figura 1 são apresentadas curvas de comportamento, descritas pelo modelo acima, para uma BGTC com módulo inicial de $15.000 \mathrm{MPa}$, denotando que, na medida em que o volume de fissuras aumenta bem como seu raio médio, a redução no valor do módulo de elasticidade seria crítica para o comportamento estrutural do material. Na Figura 2 mostra-se uma representação livre dessa estrutura de matriz heterogênea típica da BGTC.

Em geral, quando se dimensiona um dos componentes da estrutura do pavimento à fadiga (camadas estabilizadas com ligantes asfálticos ou hidráulicos), são admitidas pelo projetista (ainda que de forma inconsciente), três hipóteses básicas, conforme se seguem (Meyers e Chawla, 1998):

1. As fissuras são inerentes aos materiais. Essas 


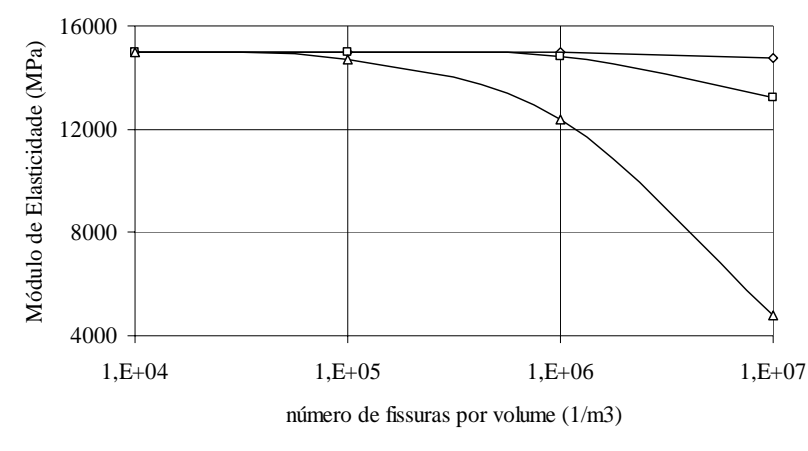

$\neg$ Fissura $=1 \mathrm{~mm} \rightarrow \square-$ Fissura $=2 \mathrm{~mm} \multimap-$ Fissura $=3 \mathrm{~mm}$

Figura 1: Degradação modular segundo Salganik (1973)

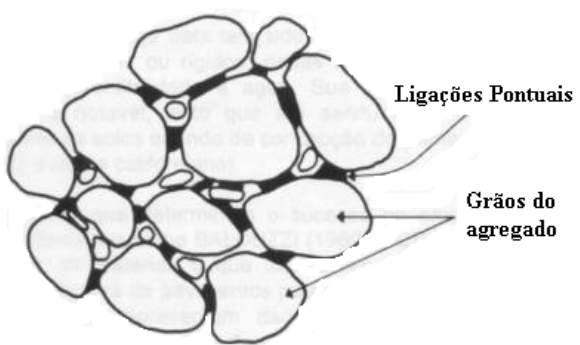

Figura 2: Estrutura interna das ligações pasta-agregado na BGTC

fissuras ocorrem por dissecação entre ligante e agregado; em conseqüência de processos de retração; ou por heterogeneidade da matriz, funcionando os poros irregulares como uma préfissuração do material.

2. Uma fissura trata-se de uma superfície plana e interna, livre na matriz, inserida em um campo de tensões elástico linear.

3. O crescimento (propagação) da fissura conduz à ruptura do material (camada) que pode ser prevista em termos de tensões de tração atuando em uma extremidade (singularidade) da fissura.

Com base nas hipóteses acima, supõe-se existência de regime elástico-linear, portanto, sem alteração do módulo de elasticidade do material durante seu processo de carregamento, seja o mesmo estático ou dinâmico. Partindo dessas hipóteses, e uma vez verificado anteriormente (Balbo e Badawy, 1993), por meio de ensaios estáticos, a possibilidade de tratamento do problema de dimensionamento dessas camadas cimentadas, em pelo menos duas zonas distintas (uma de compressão, superior, elástica não-linear; uma de tração, inferior, em regime elástico-linear), atém-se na presente análise, na questão da dosagem do material de modo a reduzir sua porosidade interna, bem como na questão da degradação modular do material ao longo de ciclos repetitivos de carregamento, tendo-se como embasamento mais contundente sua tenacidade ou resistência à fratura.

\section{DOSAGEM PARA MINIMIZAÇÃO DE MATRIZ HETEROGÊNEA}

Balbo (1993) apresentou investigações de laboratório que permitiram caracterizar uma BGTC tipicamente empregada no Estado de São Paulo, conforme especificações da DERSA e do DER-SP. As amostras, ensaiadas após 56 dias de idade, apresentavam-se bastante homogêneas umas em relação às outras (em laboratório), com coeficiente de variação na massa específica aparente seca de 0,5\% (média de 22,30 $\mathrm{kN} / \mathrm{m} 3$ com desvio padrão de $0,11 \mathrm{kN} / \mathrm{m} 3$ ); esta condição era irrevogável para os estudos de fadiga, que exigem a maior proximidade de resistência entre amostras diferentes para minimizar a inerente dispersão encontrada em tais testes.

Os corpos-de-prova foram moldados na energia modificada com umidade de moldagem cerca de $1 \%$ abaixo da umidade ótima (5,5\%), pois os estudos mostraram valores de resistência e de módulo de elasticidade cerca de $30 \%$ superiores àqueles obtidos com amostras na umidade ótima de compactação. Análises microscópicas sobre lâminas finas com espessura de $30 \mu \mathrm{m}$ em materiais com a mesma granulometria (mesmo agregado), mesmo consumo de cimento (4\% em peso), porém com umidades de compactação diferentes, permitem verificar as importantes diferenças na porosidade final das misturas compactadas.

É o caso dos resultados apresentados na Figura 3a para o material na umidade ótima e na Figura 3b para o material com umidade $2 \%$ abaixo da ótima. Os ensaios demonstraram que a amostra mais seca não aparentava água em excesso, hidratação mais fraca da pasta de cimento (em \% de cimento total), média capilaridade da pasta de cimento, ligações mais fortes cimento/agregados, em relação à situação oposta, com a mistura compactada na umidade ótima. Enfim, misturas de BGTC compactadas na energia modificada e no ramo seco da curva de compactação apresentavam matriz mais homogênea e menos porosa que aquelas amostras compactadas na umidade ótima. Tendo em vista esta situação, os estudos prosseguiram com avaliação de misturas na condição de melhor compacidade e resistência.

Na Figura 3b, a circunferência sobre a imagem representa uma zona onde se verifica claramente que a parcela de cima do agregado está circunstanciada por elevada porosidade, enquanto sua parte inferior resultou argamassada. Situações assim denotam a grande heterogeneidade da matriz na BGTC bem como zonas onde a propagação de fissuras é exacerbada durante carregamento por excesso de concentração de tensões em torno da área vazia (com aproximadamente $1 \mathrm{~mm}$ ). 

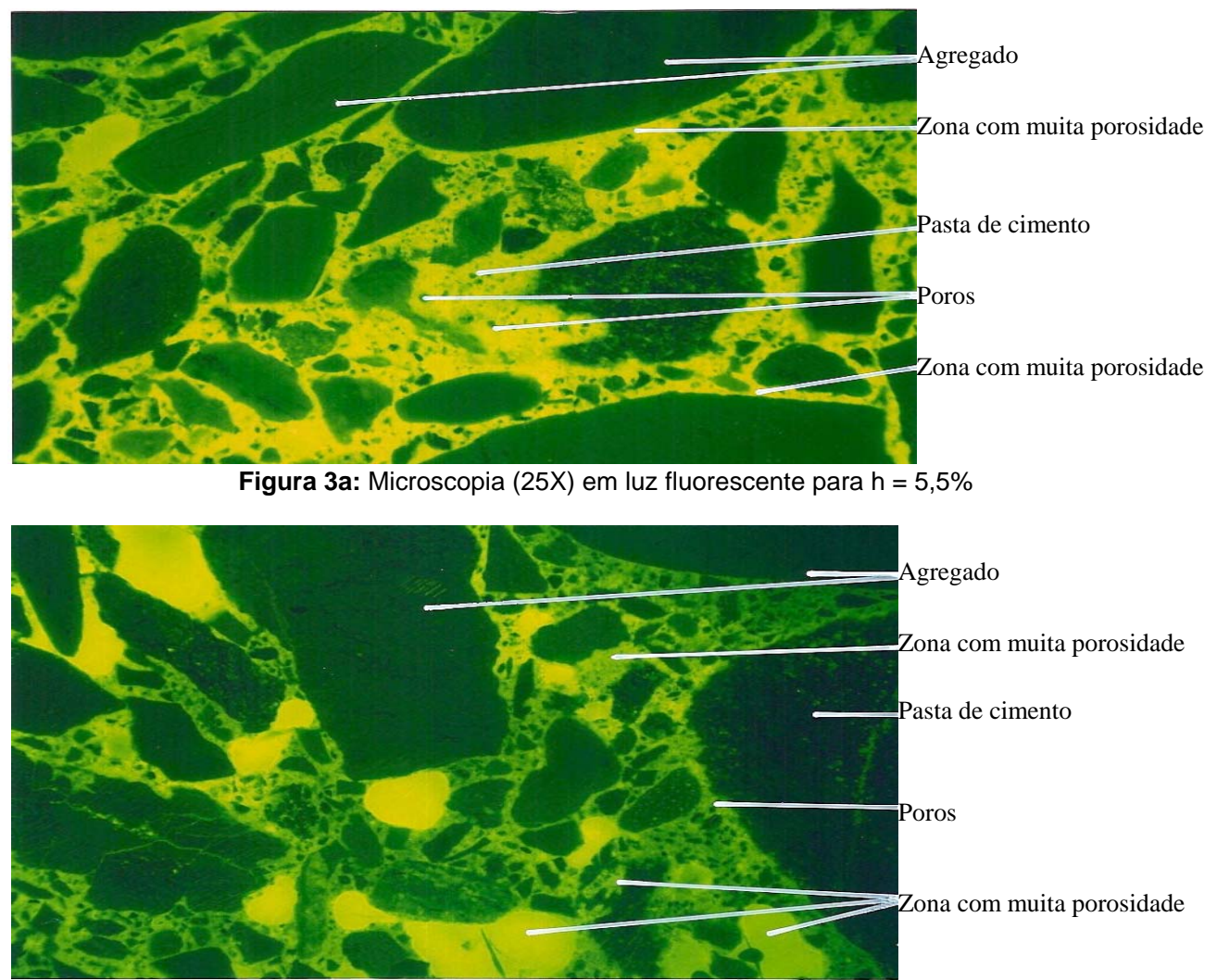

Figura 3b: Microscopia (25X) em luz fluorescente para $\mathrm{h}=3,5 \%$

\section{RESISTÊNCIA À TRAÇÃO DA BGTC}

As dificuldades de realização de testes em tração direta com o material são demonstradas simplesmente pela posição de ruptura do corpo-de-prova (Figura 4a). Durante a compactação do corpo-de-prova, feita em camadas, os estratos inferiores recebem mais energia de compactação comparativamente à camada superior (e última), que é adensada em uma série de golpes apenas. Isso acarreta uma zona superior na amostra com massa específica de cerca de $80 \%$ da massa específica das camadas inferiores.

Do ponto de vista da Mecânica de Fratura os resultados para corpos-de-prova na condição da Figura 4a não são válidos para a caracterização da amostra como um todo (Bazant e Cedolin, 1992), pois a superfície de ruptura deveria ocorrer próxima ao plano central da amostra. O corte de $20 \mathrm{~mm}$ de cada extremidade da amostra permitiu a realização de novos ensaios, com resultados válidos, já que a ruptura ocorreu então como esperada. A resistência à tração direta, para amostras após 56 dias, resultou em 1,22 MPa (com cv $=3,5 \%)$. Amostras do mesmo conjunto de moldagem resultaram em resistência à compressão uniaxial de 13,7 MPa (mais de dez vezes superior à resistência à tração do material).

Esta condição peculiar levou à adoção de ensaios de tração (indireta) por compressão diametral em corposde-prova idênticos aos anteriores, posto que nesse ensaio o plano de fratura é previamente definido, coinci- dindo com o plano de aplicação de cargas. A verificação se de fato tal condição ocorreria foi verificada visualmente nas amostras, sendo que em contrário não teria validade também a medida dessa resistência; ou seja, se durante este tipo de ensaio planos paralelos ao plano principal de fratura (vertical) também ocorrem, com estrias laterais nas amostras, o ensaio de compressão diametral não mede a resistência corretamente (Rocco et alli, 1998).

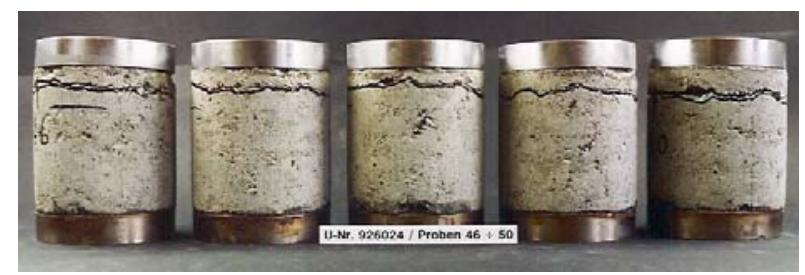

Figura 4a: Condição dos corpos de prova após ruptura à tração direta

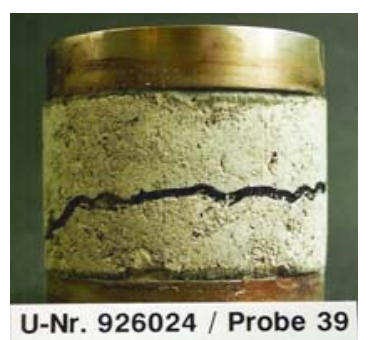

Figura 4b: Condição de ruptura após redução da altura

Os testes realizados resultaram em resistência à tração média de 2,34 MPa, ou seja, o dobro da resistência média aferida por tração direta. Note-se que há uma combinação de zonas mais resistentes e menos 
resistentes no plano de fratura do corpo-de-prova devido às condições de compactação já esclarecidas anteriormente. Além disso, dada a existência de zona mais resistente na seção de atuação da carga, é possível a ocorrência de gradientes de esforços mais concentrados nessa zona, o que torna o ensaio mais complexo para interpretação.

Não há, todavia, muito que comemorar com o pequeno valor, porém significativo em comparação a misturas solo-cimento, de resistência à tração apresentada pela BGTC, do ponto de vista da deformação de ruptura aferida durante os ensaios, que variou de 0,03 a $0,05 \%$. O coeficiente de dilatação térmica do material é da ordem de $10-6{ }^{\circ} \mathrm{C}^{-1}$, o que significa que uma variação térmica no material, de $10^{\circ} \mathrm{C}$, seria suficiente para sua ruptura, o que coloca novamente a questão da fissuração do material, em limites críticos, mesmo para cargas exclusivamente ambientais.

\section{PLASTIFICAÇÃO DA BGTC AO LONGO DE CICLOS REPETIDOS DE CARREGAMENTO (FADIGA)}

Na Figura 5 é apresentada a evolução da deformação (deslocamento) vertical sobre amostras submetidas a ensaio de compressão diametral (tração indireta) para análise de fadiga, considerando casos de amostras que sobreviveram aos ensaios cíclicos (dinâmicos) entre $10^{3}$ e $10^{6}$ repetições de carga.

Os ensaios foram realizados na freqüência de 10 $\mathrm{Hz}$, ou seja, em uma velocidade tal que a carga não atua tempo suficiente sobre o material de maneira a aumentar as tensões críticas de abertura de fissuras, o que ocorreria a $1 \mathrm{~Hz}$ com grande facilidade; assim a propagação de fissuras se dá de modo mais paulatino. Como Cervo (2004) mostrou cabalmente para concretos com matriz homogênea, o comportamento à fadiga observado em laboratório, quando os ensaios são realizados a elevadas freqüências, tende a ser otimista em relação ao comportamento à fadiga do material em pista.

Em todos os casos, verifica-se um acréscimo exagerado no valor da deformação medida para os últimos carregamentos antes da ruptura, o que em geral ocorreu para menos de dez ciclos finais de carregamentos em qualquer um dos casos. Nota-se assim, na vida final de fadiga, uma degradação crítica e acelerada, com intensa ruptura do material, de modo que a fratura ocorre quase que subitamente nesse final de teste. Todavia, a escala representada na Figura 5 não permite visualizar a degradação ao longo da vida de fadiga do material, que é mais bem representada na Figura 6 .

Observa-se na Figura 6, ampliada a escala para os ciclos de fadiga durante os testes, um crescimento importante, desde o princípio do ensaio, do valor da deformação. Inclusive, é evidenciado pelos resultados que quando o mesmo material é submetido a maior esforço repetitivo, as taxas de crescimento de deformação são maiores, induzindo ruptura por fadiga mais rapidamente, como no caso da amostra S14. A amostra S21, por sua vez, apresentou menor taxa de degradação, aqui entendida pelo aumento da deformação plástica, ao longo do teste, devido a menor esforço repetitivo dentre as demais.

Tais resultados apóiam a assertiva de Suresh (1998) de que "tensões associadas à fadiga em poucos ciclos são geralmente elevadas o suficiente para causar deformação plástica antes da fadiga”. Inclusive, em materiais semi-frágeis, quando além de ruptura de ligações atômicas a resistência à fratura é ditada também pela mobilidade, ou seja, por deslocamentos entre partículas (escorregamentos), um limitado fluxo plástico (ou fluência) ocorre antes da ruptura frágil propriamente dita (Suresh, 1998). Por fim, seguindo um padrão de material de ruptura frágil, há escorregamento friccional na região de interface no sistema multifásico (agregados + pasta de cimento).

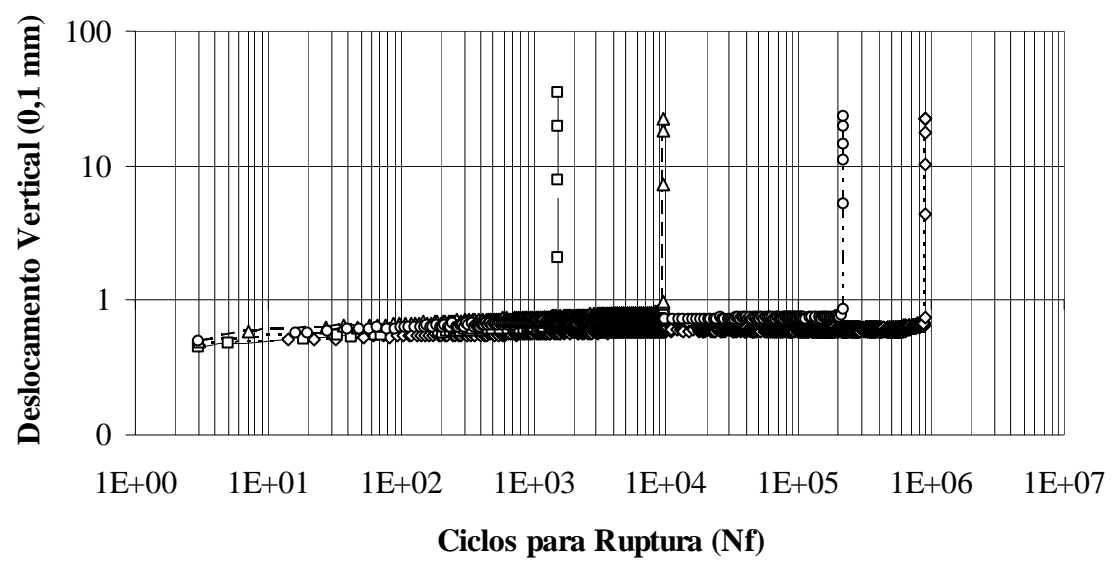

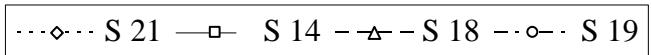

Figura 5: Ciclos completos de vida de fadiga da BGTC até ruptura 


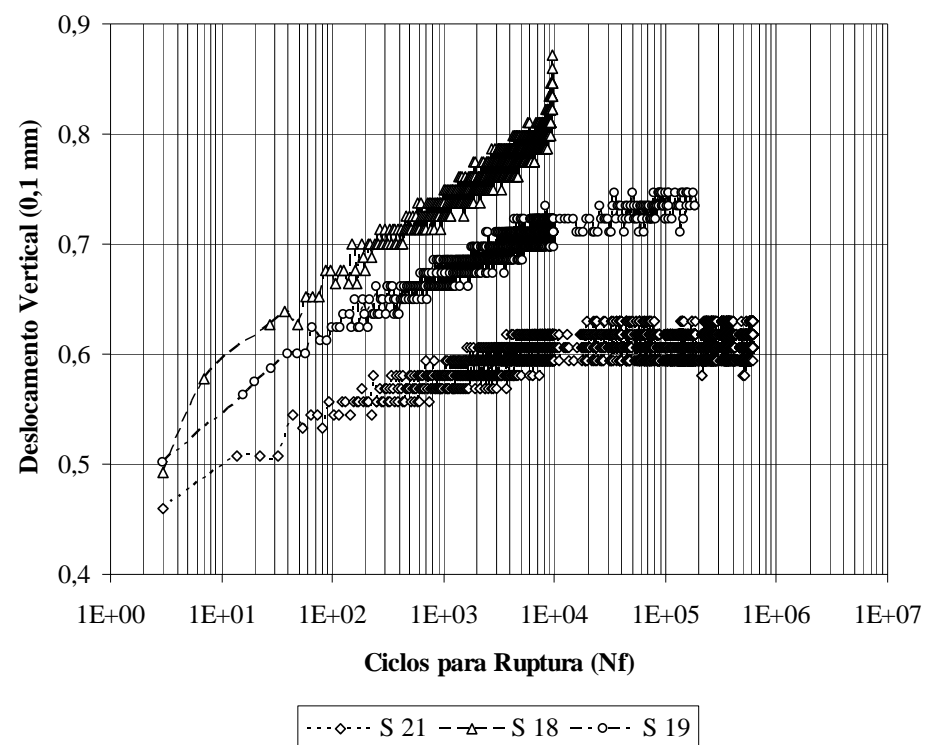

Figura 6: Ciclos de vida de fadiga da BGTC em pré-ruptura

Ocorre, portanto, plastificação por acomodação, ou seja, por ruptura de ligações mais fracas, desde o início do carregamento cíclico do material. Como em um ensaio de fluência, observa-se uma fase inicial com maior taxa de crescimento da deformação e essa taxa é maior quanto maior o nível de tensão aplicada ao material. Em uma segunda fase, há tendência de um crescimento constante da deformação, porém a taxa menor. Essa taxa de crescimento, após acomodação inicial (de dez a cem ciclos iniciais), tende mesmo a zerar quando são baixas as tensões aplicadas, mantendo-se assim o material sem deformações plásticas (estável) durante todo seu restante de serviço em fadiga (como aparenta o caso para SSR $=0,57$, com valores de deformações estáveis em sua média entre $10^{4}$ e $10^{6}$ ciclos de carregamento).

Os resultados são úteis para o esclarecimento de que, durante toda a fase de solicitações repetidas no material, ou seja, durante todo seu uso pelo tráfego na estrutura de pavimento, ele sofre degradação modular progressiva já que a deformação aumenta; isto melhor se configura para relações entre tensões mais elevadas; em outras palavras, seu módulo de elasticidade encontra-se em constante decréscimo por degradação desde o início de sua vida de serviço, podendo a deformação atingir acréscimos da ordem de $100 \%$ quando a matéria ainda apresenta continuidade. Fica conotado, portanto, um mecanismo de propagação instável de fissuração sem aumento do carregamento externo. $\mathrm{O}$ valor do módulo de elasticidade reduz pelo aumento da extensão da fissura bem como pela nucleação de novas fissuras, seguindo a tendência apresentada na Figura 1.

Ora, é evidente que esta condição viola gravemente uma das hipóteses de projeto, qual seja, o não atendimento do material a essa hipótese (não à Teoria do
Dano Continuo Linear em si mesma). Para se manter a mente aberta a esta enorme dificuldade, bastaria dizer que em várias fases de utilização do material seu módulo de elasticidade é diferente e seu próprio comportamento à fadiga seria alterável, e não explicado por uma equação linear simples, como costumeiramente se propõe de modo a simplificar a análise.

Este comportamento (de degradação lépida) está relacionado à pequena quantidade de pasta de cimento, incapaz de causar o envolvimento completo de grande parte dos grãos do agregado, o que certamente, somado à estrutura extensa de poros dentro do material, gera numerosas zonas de vazios, onde há exacerbada concentração de tensões e, portanto, de propagação das fissuras, de forma mais acelerada que em um material cimentado com matriz homogênea (coisa que, ao contrário de um concreto, a BGTC definitivamente não é).

O aumento de deformação (plastificação), desde o princípio, é indicativo de nucleação e propagação de fissuras na estrutura interna do material, de maneira bem intensa. Isto poderia ser reduzido e melhor controlado, procurando-se uma redução em sua porosidade e o melhor envolvimento dos agregados e o preenchimento dos espaços livres entre eles pela pasta de cimento.

Ora, a última condição acima encaminharia, sine quae non, para uma mistura diferente da BGTC, quando o consumo de cimento deveria ser incrementado em pelo menos algo em torno de 50 a 100\%, passando, portanto, para até $150 \mathrm{~kg} / \mathrm{m}^{3}$ de material; ou seja, tratar-se-ia o material de um CCR, portanto, de um concreto, e não mais de um material meramente estabilizado ou tratado com cimento.

Mantida a condição de BGTC para o material, a única maneira restante de minimizar o fenômeno seria 
a redução da porosidade na estrutura interna do mesmo, o que pode ser obtido com maior energia de compactação (redução da umidade ótima em relação a energias menores) para ganho de massa específica aparente seca, bem como por meio da compactação do material no ramo seco, como se verificou anteriormente. Porém, entendidas tais sugestões como soluções paliativas, haja vista que a matriz da BGTC continuará inexoravelmente aberta e heterogênea, e bastante suscetível à fratura, desta forma.

\section{RESISTÊNCIA À FRATURA DA BGTC (TENACIDADE)}

Esta consumada incapacidade do material BGTC em termos estruturais pode ser também comparada com os concretos por meios de ensaios de tenacidade à fratura, que trazem maiores luzes à interpretação da relação entre desenvolvimento da fratura, por meio da medida do deslocamento de abertura da entrada do entalhe (CMOD - crack mouth opening displacement), e, portanto, degradação estrutural do material, com intuito também de estabelecer dosagem que encaminhe para as melhores características desejáveis para uma BGTC, em caso de seu emprego.

A tenacidade pode ser definida como a quantidade de energia absorvida por qualquer material durante seu processo de desenvolvimento de fratura estrutural (a partir do início da fratura), sendo que estruturas com materiais de alta resistência normalmente apresentam baixa resistência ao fraturamento (Broeck, 1986). Nestas condições, os concretos com matrizes homogêneas e muita pasta envolvendo os grãos apresentariam a desvantagem de ruptura quase-frágil, ou seja, resguardando baixa quantidade de energia durante o fraturamento.

Para estudar esta propriedade, corpos-de-prova idênticos aos demais foram trabalhados para viabilizar ensaios de tenacidade. Na Figura 7 é mostrado o arranjo preparado para os ensaios de fratura com corpos-de-prova cilíndricos com dimensões idênticas àqueles empregados para ensaios à fadiga, o que denota um teste de fratura no Modo I (abertura), em tração, com aplicador em cunha que causa o distanciamento de dois cilindros encaixados no corte acima do entalhe no corpo-de-prova (deslocamento horizontal). As amostras foram ensaiadas após 56 dias de cura, sendo aplicada velocidade de carregamento de $0,010 \mathrm{~mm} / \mathrm{s}$, sendo os resultados obtidos para diagramas forçaabertura (da fissura) conforme indicados na Figura 8.

Há três zonas bem distintas observadas nos ensaios de fratura, conforme resultados da Figura 8. Na primeira zona, que engloba a parte da curva de tenacidade da origem até cerca de $50 \%$ antes do pico da força
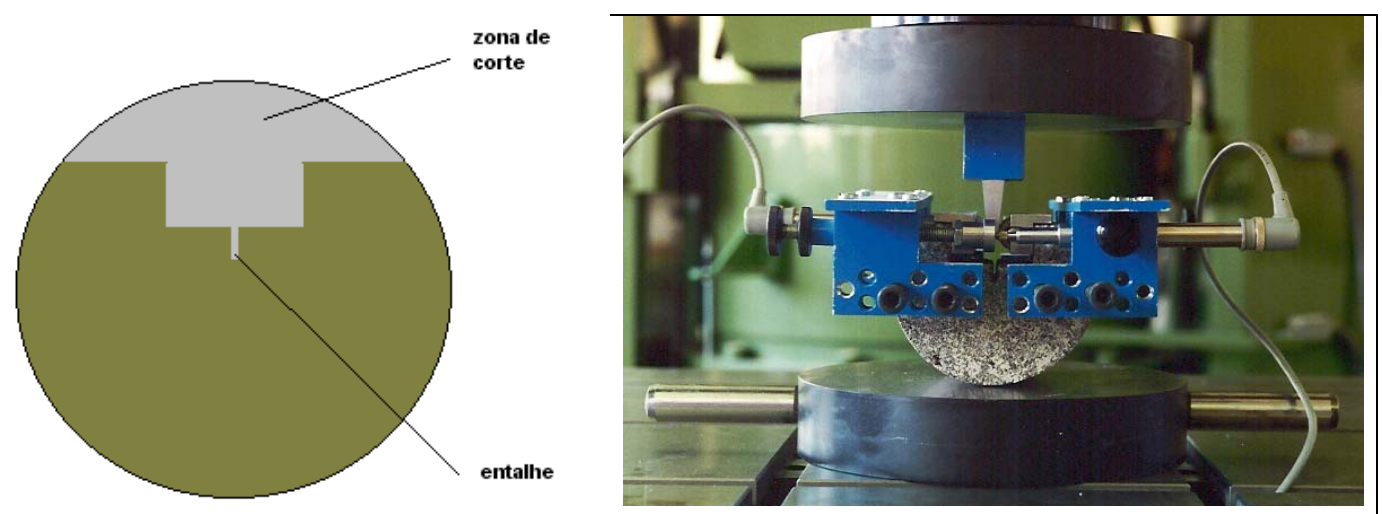

Figura 7: Formato do entalhe e arranjo do ensaio de fratura

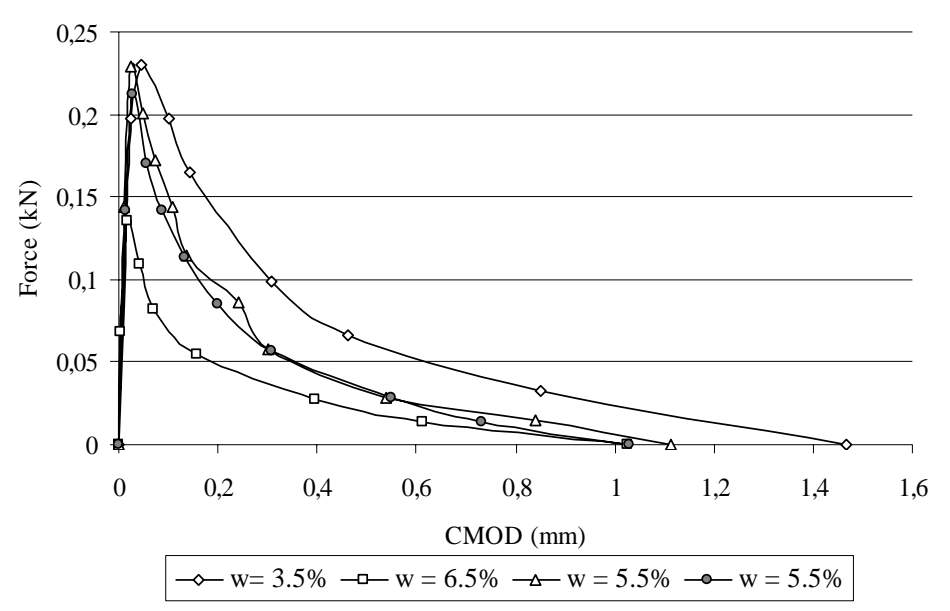

Figura 8: Diagramas de tenacidade para a BGTC em várias umidades de compactação 
aplicada, há um crescimento disperso das fissuras, podendo-se considerar um comportamento praticamente linear do material. Na segunda zona do ensaio, tem-se uma formação de processos inelásticos, quando se tem o processamento da fratura; o deslocamento de abertura da ponta do entalhe (CTOD - crack tip opening displacement) ainda não é crítico bem como o fator de intensidade de tensões $\left(\mathrm{K}_{\mathrm{I}}\right)$ ainda não atinge seu valor crítico (a partir do qual uma fissura com uma dada dimensão passa a crescer de maneira instável).

É também denominada tal zona por estágio précrítico ou sub-crítico, antecedendo, portanto, à formação da fissura principal que virá a ocorrer por coalescência entre as microfissuras na estrutura interna do material. Esse deslocamento inelástico é condicionado por diversos fatores além da própria microfissuração, como a fluência apresentada pelo material, o intertravamento entre os agregados, o atrito nas faces da fissura.

Ao atingir o pico da força, tem-se o valor de $\mathrm{CTOD}_{\mathrm{c}}$ crítico e o fator de intensidade de tensões é estável e crítico. Na terceira fase, entre o pico (carga máxima) e o final da abertura da fissura (final de propagação), quando as partes da matéria se dividem, tem-se um estágio de continuidade de crescimento da fissura (CMOD) com diminuição da carga aplicada. Esta área sob a curva, após o ponto de carga máxima, também chamada de zona pós-pico, é aquela que caracteriza a tenacidade (resistência à fratura) e a energia absorvida durante o processo pelo material.

Observa-se das curvas força-deslocamento apresentadas na Figura 8 que as misturas com maior resistência, portanto, aquelas compactadas na menor umidade, apresentam tenacidade à tração inferior, analisadas as curvas pós-pico, que aquelas compactadas na umidade ótima (5,5\%), embora se tratem de pequenas diferenças; portanto, a fragilidade do material aumentaria quando compactado no ramo seco, em sentido contrá- rio ao aumento de resistência esperado. Valores de umidade acima da ótima, de acordo com os resultados, além de tornar o material pouco resistente, seriam desfavoráveis para sua tenacidade, que resultaria bem menor que para a umidade ótima de compactação.

Assim, o aumento de resistência à fratura, apresentado pela BGTC, para menores umidades de compactação, significa também um aumento de fragilidade do material em comparação às misturas compactadas com maior umidade. Em todos os casos, todavia, verificase um comportamento quase-frágil do material, sendo que durante seu processo de fratura há liberação de energia de plastificação antes da fratura propriamente dita. O material resguarda, portanto, deformações plásticas antes de fissurar por completo, apresentando assim alguma fluência durante o carregamento, conforme se verificou na Figura 6 .

Por conseguinte, a BGTC não pode, de maneira alguma, ser tomada com paralelismos a concretos, do ponto de vista de seu fraturamento. Na Figura 9 temse uma comparação entre os resultados de ensaios de fratura para o material estudado $\left(\mathrm{f}_{\mathrm{ck}}=14 \mathrm{MPa}\right)$ e para concretos convencionais para estruturas $\left(\mathrm{f}_{\mathrm{ck}}=\right.$ $30 \mathrm{MPa}$ ). A tenacidade de um concreto, portanto com matriz homogênea, é de longe muito superior àquela da BGTC, denotando a enorme fragilidade relativa do material cimentado. Assim, módulos de elasticidade muito próximos podem não significar nada em termos de comportamento à fratura, como se verifica dos estudos realizados, pois a BGTC apresenta módulo de elasticidade bem próximo àqueles dos concretos compactados com rolos. A baixíssima tenacidade da BGTC demonstra também quão mais veloz seria a propagação da fissura, para uma mesma carga, em relação a um concreto (compactado ou adensado), conotando, em decorrência disso, comportamento à fadiga medíocre em comparação aos concretos.

O material BGTC, tratado com cimento ou cimen-

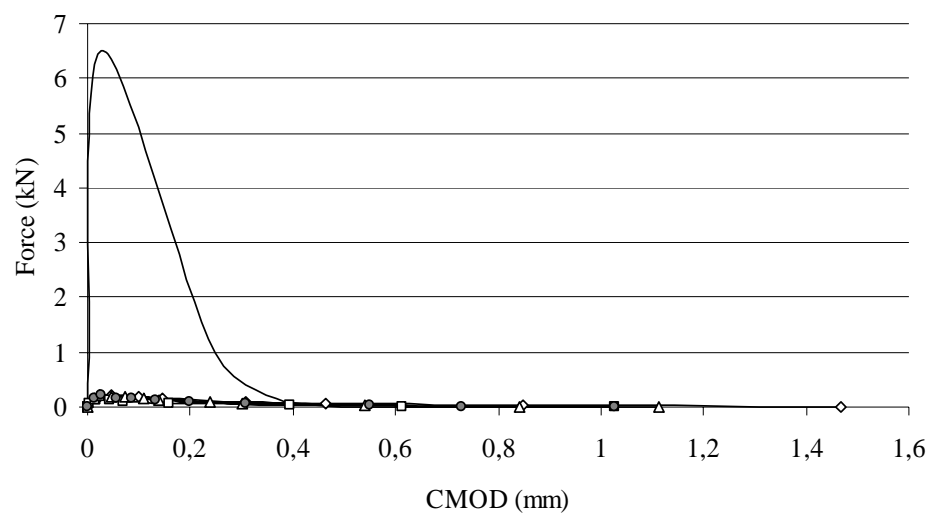

$\begin{array}{ll}\multimap \mathrm{w}=3.5 \% & \rightarrow-\mathrm{w}=6.5 \% \\ \multimap \mathrm{w}=5.5 \% & \multimap-\mathrm{w}=5.5 \% \\ \multimap \text { Concrete (Ferreira, 2002) } & \end{array}$

Figura 9: Diagramas de tenacidade da BGTC e de concreto com fck $=30 \mathrm{MPa}$ 
tado, como se deseje referenciá-lo, trata-se, dessa forma, de mistura altamente suscetível a processos de fratura, dada sua matriz heterogênea e elevado número de nucleações de vazios iniciais, em especial para níveis médios e elevados de tensões (SSR > 0,6). Seu projeto como elemento constituinte de estruturas de pavimentos e pisos industriais, necessitaria, por assim se dizer, para obter grande longevidade sem degradação excessiva, resguardar baixas tensões de trabalho (baixas relações entre tensões). Isto representa uma necessária alteração na concepção de projeto do material: não abandonando a análise de seu comportamento à fadiga, ainda que limitadíssimo nos moldes convencionais, o material deveria ser concebido para sofrer esforços máximos da ordem de $50 \%$ de sua tensão de ruptura à tração, embora seja ainda assim uma medida propedêutica e não categoricamente garantida, pois limites de sobrevivência ilimitada à fadiga não foram seguramente estabelecidos para concretos, nem mesmo para aços. O que dizer para a BGTC?

\section{CONCLUSÕES}

Os dados objetivos experimentalmente aferidos e aqui apresentados vêm confirmar o comportamento de inúmeros pavimentos semi-rígidos, não somente com base em BGTC como também com base em solocimento, que apresentaram, unanimemente e inexoravelmente, fissuração intensa após alguns anos de serviço. A problemática de bases de pavimentos asfálticos deteriorados, no caso bases cimentadas em intenso processo de fadiga, tem colocado os técnicos rodoviários, acadêmicos ou práticos, diante de uma situação paradoxal. Ou se remove a base degradada ou se buscam meios, alguns aparentemente pouco eficientes, de evitar a propagação das fissuras abertas nas bases cimentadas para as novas camadas asfálticas de reforço. Trata-se, portanto, de uma limitação importante e inerente aos materiais de base e de sub-base de pavimentos estabilizados com ligantes hidráulicos.

Mecanicamente, a base após fissurar, funciona como um conjunto de blocos que fornece incontáveis entalhes para a abertura de fissuras e sua posterior propagação ascensional na camada de revestimento asfáltico, apenas pelo contato, que criam uma descontinuidade na distribuição de tensões na interface, concentrando-se as mesmas na face inferior do revestimento asfáltico, que muitas vezes é induzido à fissura prematura por essa contingência.

A camada superior, respondendo em flexão e estando plenamente aderida à base fissurada, para cada situação de carga funciona como um entalhe de abertura progressiva, como visto, nos testes experimentais realizados. Observe que, por efeitos de retração térmica, durante o uso do pavimento, a abertura dessas fissuras nas bases cimentadas poderá ser bem significativa, forçando inúmeras fissuras iniciais nas interfaces de contato revestimento-base. Bloquear tais efeitos, de maneira eficiente comprovadamente, parece ainda não ser objeto de consenso.

A remoção de uma base deteriorada, do ponto de vista operacional e com base nos custos recorrentes, por outro lado, tem se mostrado inviável como demonstram vários trechos das Avenidas Marginais em São Paulo, construídas na segunda metade da década de 1960 e submetidas ao maior volume de veículos comerciais que ocorre no país, bem como em rodovias como a dos Imigrantes e a Ayrton Senna (antiga dos Trabalhadores). O mesmo se dá em relação a milhares de quilômetros construídos com bases em solocimento no Estado de São Paulo nos últimos 40 anos.

De tal sorte que, para atender a ambos os problemas, de maneira mais adequada em novas construções, resta apenas, quando do emprego de bases rígidas e sujeitas à fratura e fadiga subseqüente, buscar materiais com matriz de argamassa mais homogênea, que ofereçam elevada resistência estática e dinâmica (à fadiga), além de melhor tenacidade (melhor resistência à fratura), o que faria com que a ocorrência de fissuras retrocedesse ao máximo. A BGTC, com sua peculiar heterogeneidade na matriz, o que gera uma enormidade de poros e descontinuidades em sua estrutura interna durante o processo de sua execução, inclusive sujeita a muita segregação, trata-se de material que oferece baixíssima resistência à fratura, sendo bastante suscetível ao fenômeno da fadiga, comparado a outros materiais à base de ligantes hidráulicos e executados com os mesmos equipamentos de pavimentação (rolos compressores).

Prejudica ainda, causando maior heterogeneidade na matriz da BGTC, sua inerente segregação durante seu transporte entre a usina de misturação (de agregados) e a pista. Nesse aspecto, um material que fosse transportado e continuamente misturado até sua aplicação em pista, como é o caso do CCR, seria bastante vantajoso ao vencer mais folgadamente os inerentes processos de segregação.

Desta maneira, a longevidade da base rígida seria tal que, as mazelas de necessárias reconstruções fossem lançadas para um futuro bastante distante, em geral superior a três décadas. Dois tipos básicos de materiais podem atender a tais requisitos: o concreto, que por reducionismo poderia ser aquele mais econômico, ou seja, o concreto compactado com rolo; alternativamente, misturas asfálticas com CAP de elevada viscosidade (consistências entre 10 e 20 décimos de milímetros), que ofereceriam ainda a vantagem de não apresentar contrações volumétricas iniciais em relação a misturas com médio a elevado consumo de ligantes hidráulicos. 
Os níveis de tráfego atuais, com padrões diários da ordem de dezenas de vezes superiores aos padrões de rodovias de tráfego pesado da década de 1960, exigem materiais para bases compatíveis com as solicitações cíclicas das cargas: bastante resistentes à fratura e à fadiga. Em tal contexto, não há mais como conceber o emprego de BGTC para rodovias de tráfego pesado dadas suas insanáveis limitações, restando às mesmas o papel de bases de elevado desempenho para vias de baixo volume de tráfego, observado ainda que a relação entre tensões aplicadas e resistência à flexão do material deverá ser mantida em torno de 50\% para se evitar sua precoce plastificação e fratura.

Projetos inteligentes para vias de tráfego pesado devem necessariamente contemplar o emprego de bases com misturas, asfálticas ou cimentadas, de elevada rigidez; porém, misturas com matriz homogênea e uniforme, pouco propensas à fratura, requisito esse que a BGTC não perfaz. Assim, torna-se antiquado e inconsistente, inclusive desfavorável ao erário público, em muitos casos, a concepção de tradicionais pavimentos semi-rígidos, convencionais ou invertidos. $\mathrm{O}$ nível de conhecimento tecnológico existente permite, após reflexões, chegar-se a soluções mais inteligentes nesses casos.

\section{REFERÊNCIAS BIBLIOGRÁFICAS}

Balbo, J. T. (1993) Estudo das propriedades mecânicas das misturas de brita e cimento e sua aplicação aos pavimentos semi-rígidos. Tese (Doutorado), Escola Politécnica. Universidade de São Paulo, São Paulo.

Balbo, J. T. e Badawy, M. (1993) Britas graduadas tratadas com cimento: elasticidade linear ou não linear? Anais do VII ANPET Congresso de Pesquisa e Ensino em Transportes, Vol.2, pp. 915-922, São Paulo.

Balbo, J. T. (1996) Critério de verificação à fadiga para pavimentos semirígidos. Anais do X ANPET Congresso de Pesquisa e Ensino em Transportes, Vol.2, pp. 771-779, Brasília.

Balbo, J. T. e Rodolfo, M. P. (2003) Modelagem de tensões em pavimentos de concreto com base aderida e diferenciais térmicos. Anais do XVII ANPET Congresso de Pesquisa e Ensino em Transportes, Vol.1, pp. 323-334, Rio de Janeiro.

Balbo, J. T. (2005) Pavimentos asfálticos híbridos-rígidos: perspectivas para baixos a elevados volumes de tráfego. Anais da 36 $6^{a}$. Reunião Anual de Pavimentação (Cd-rom), Associação Brasileira de Pavimentação, Curitiba.

Bazant, Z.P. e Cedolin, L. (1992) Why direct tension specimens flex and break at midlength. Proceedings, 1st Int. Conf. on Fracture Mechanics of Concrete Structures, Elsevier Applied Science, Colorado.

Broeck, B. (1986) Elementary Engineering Fracture Mechanics. Martinus Nijhoff Publishers, Dordrecht, The Netherlands.

Cervo, T. C. (2004) Estudo da resistência à fadiga de concretos de cimento Portland para pavimentação. Tese (Doutorado), Escola Politécnica da Universidade de São Paulo, 220 p., São Paulo.

Ferreira, L.E.T. (2002) Sobre a resistência ao fraturamento do concreto e do concreto reforçado com fibras de aço. Tese (Doutorado), Escola Politécnica, Universidade de São Paulo, São Paulo.

Meyers, M. A. e Chawla K. K. (1999) Mechanical Behavior of Materials, Prentice-Hall.

Rocco, C. et al. (1998) Experimental analysis of rupture mechanisms in the Brazilian test. Proceedings, FRAMCOS, pp. 121-130.

Salganik, R.L. (1965) The strength of adhesive joints using the theory of cracks. Int. Journal of Fracture Mechanics, 1, 114-128.

Suresh, S. (1998) Fatigue of Materials. 2nd. edition, Cambridge Press, Boston. 